Scientific Paper

\title{
Patient dose measurement in common medical X-ray examinations and propose the first local dose reference levels to diagnostic radiology in Iran
}

\author{
Behrouz RASULI ${ }^{1}$, , Raheleh TABARI JUYBARI ${ }^{1}$, Meysam FOROUZI ${ }^{1}$, Mohammad GHORBANI ${ }^{1}$ \\ ${ }^{I}$ Department of Radiology Technology, Behbahan Faculty of Medical Sciences, Behbahan, Iran \\ rasuli-b@ajums.ac.ir \\ (received 4 April 2017; revised 7 July 2017; accepted 12 July 2017)
}

\begin{abstract}
Introduction: The main purpose of this study was to investigate patient dose in pelvic and abdomen x-ray examinations. This work also provided the LDRLs (local diagnostic reference levels) in Khuzestan region, southwest of Iran to help establish the NDRLs (national diagnostic reference levels).

Methods: Patient doses were assessed from patient's anatomical data and exposure parameters based on the IAEA indirect dosimetry method. With regard to this method, exposure parameters such as tube output, $\mathrm{kVp}, \mathrm{mAs}$, FFD and patient anatomical data were used for calculating ESD (entrance skin dose) of patients. This study was conducted on 250 standard patients (50\% men and 50\% women) at eight high-patient-load imaging centers.

Results: The results indicate that mean ESDs for the both pelvic and abdomen examinations were lower than the IAEA and EC reference levels, 2.3 and $3.7 \mathrm{mGy}$, respectively. Mean applied kVps were 67 and 70 and mean FFDs were 103 and 109, respectively. Tube loadings obtained in this study for pelvic examination were lower than all the corresponding values in the reviewed literature. Likewise, the average annual patient load across all hospitals were more than 37000 patients, i.e. more than 100 patients a day.

Conclusions: The authors recommend that DRLs (diagnostic reference levels) obtained in this region, which are the first available data, can be used as local DRLs for pelvic and abdomen procedures. This work also provides that on-the-job training programs for staffs and close cross collaboration between physicists and physicians should be strongly considered.
\end{abstract}

Key words: diagnostic reference level; entrance skin dose; Iran; patient dose; radiographic examination.

\section{Introduction}

In recent years with the progress of medical sciences, the development rate of novel X-ray technologies in the clinical setting has increased and nowadays plays a pivotal role in the diagnostic decision making. These devices are the most common human-made source of ionizing radiation and the amount of radiation received by patients is gradually on the rise. Therefore, the received dose and their associated risks, including the probability of radiation-induced cancer as well as biological complication, should pay strict attention to ensure that it remains at the appropriate level.

Several patient dose surveys have been performed around the world during the past decades and comparison has been carried out on obtained results with DRLs (dose reference levels) reported by international legislative organizations like the IAEA (International Atomic Energy Agency) and EC (European Commission) [1-6]. Some developed countries have drawn up a comprehensive NDRLs (national dose reference levels) plan for X-ray examinations based on the ICRP
(International Commission on Radiological Protection) recommendations $[7,8]$ and try to update it regularly.

There is neither regulated radiation protection procedures nor established NDRLs in Iran. The challenges facing Iran are to build the healthcare infrastructures, to provide medical imaging equipment and try to attract qualified specialists with the limitation of financial resources [9,10]. Few patient dose assessments have been conducted in Iran [11-17]. Iran also did not participate in the IAEA international patient dose survey, which makes these types of studies more important [18]. This contribution is the first steps into establish dose audits and optimizations of patient dose in conventional radiology examinations, including pelvis and abdomen procedures in Khuzestan region, southwest of Iran. These procedures were selected based on their frequencies and contribution to the collective dose delivered to the public. This study also provides the LDRLs (local dose reference levels) in Khuzestan region, southwest of Iran to help establish the national dose reference levels across Iran. 


\section{Materials and Methods}

This study was conducted from October to December 2015 at eight medical imaging centers (C1-C8) of public and educational hospitals in southwest of Iran. Abdomen and pelvis radiographic examinations were selected in AP (anteriorposterior) view. ESD (entrance skin dose) is a well-defined parameter that was considered in this work for patient dose evaluation. By definition, it is the entrance dose at the skin surface of an adult standard patient taking into account scattered X-rays. In this study, the indirect dosimetry approach has been adopted according to the IAEA Report Series No. 475 [19]. With regard to this sound approach, exposure parameters such as tube output, kVp, mAs, FFD and patient's anatomical data were used for calculating ESD, using a calibrated Barracuda X-ray MPD (multi-purpose detector) (RTI Electronics AB, Mölndal, Sweden) and pure Aluminum HVL filters. Prior to main experiments, quality control tests were performed on all the X-ray machines and darkroom equipment using the MPD and an Alpha test phantom (PEHA med. Geräte $\mathrm{GmbH}$, Sulzbach, Germany), according to the IPEM (Institute of Physics and Engineering in Medicine) Report No.91 method [20].

\section{Data acquisition}

With reference to the IAEA method, at least ten standard patients (weight $70 \pm 10$ kilograms $(\mathrm{Kg})$ ) including male and female should be assessed for any procedure. Therefore, 250 patients (125 men and 125 women) were entered into the study. Patients were asked to declare their weight, then the thickness of abdomen and pelvis were measured if the weight was in accordance with the standard patient. Obese patients (BMI $\geq 30$ $\mathrm{kg} / \mathrm{m}^{2}$ ) and infants were excluded from the process. Full technical information of X-ray machines was recorded in each imaging centers as shown in Table 1. Also, patient information including weight, abdomen and pelvis thickness, age and gender as well as exposure setting ( $\mathrm{kVp}, \mathrm{mAs}$ and FFD) were recorded for any procedure by trained technologists in a predesigned datasheet. Written informed consent were obtained from all participants prior to their inclusion in the study.

\section{Indirect dosimetry}

As illustrated in Figure 1, thickness of the patient under examination (abdomen and pelvis) was measured at the center of the radiation field with respect to the orientation of radiation field (AP), from the tabletop to the skin surface by a typical measuring tape.

ESD can be obtained for any examination using the following formula:

$E S D=$ Tube output $\times m A s \times\left(\frac{d}{d_{F T D^{-} t_{p}}}\right)^{2} \times B S F$

Tube output was measured by placing MPD at distance $\mathrm{d}$ from the X-ray tube, mAs is the tube loading, $\mathrm{d}_{\mathrm{FTD}}$ is the distance between the $\mathrm{X}$-ray tube and tabletop and $t_{p}$ is the thickness of abdomen or pelvis. BSF (has no unit) stands for backscatter factor that depends on HVL, $\mathrm{kVp}$ and field size and can be obtained according to the IAEA Technical Reports Series No. 457 appendix VIII [19]. It is noteworthy that measurement of tube output was performed in the quality control phase prior to main experiments. There are not any real patients during dosimetry and tube output measurements.

\section{Results}

Table 1 presents technical characteristics of X-ray units, image receptors, tube output (at $80 \mathrm{kVp}$ ) and $\mathrm{HVL}$ (at $70 \mathrm{kVp}$ ) for all imaging centers. The average annual patient load across all centers are more than 37000 patients. The average age of devices was 15 years. There has been frequent repairs on devices and replacement of accessories except C3 unit. Based on the IEC 1223 (International Electrotechnical Commission) and the IPEM Report No. 91, X-ray tube output in the range between 43-52 $\mu \mathrm{Gy} / \mathrm{mAs}$ is known as "Good", 26-43 $\mu \mathrm{Gy} / \mathrm{mAs}$ and 52-69 $\mu \mathrm{Gy} / \mathrm{mAs}$ are "Normal" and $<26$ and $>$ $69 \mu \mathrm{Gy} / \mathrm{mAs}$ is "Poor" criteria [20]. Therefore, C2 and C3 units met "poor" tube outputs, 72.7 and $104.3 \mu \mathrm{Gy} / \mathrm{mAs}$, respectively. Likewise, the minimum $\mathrm{HVL}$ at $70 \mathrm{kVp}$ should be at least $2.1 \mathrm{~mm}$ of $\mathrm{Al}$, so all the X-ray machines met the minimum required $\mathrm{HVL}$ at $70 \mathrm{kVp}$ except the $\mathrm{C} 3$ unit $(1.9 \mathrm{~mm}$ of $\mathrm{Al}$ ). The AEC (automatic exposure control) system either did not exist or could not be used, consequently manual exposure setting was common. As shown in Table 1, all centers had conventional radiology devices and were using SF (screen-film) with 400 speed classes. Also, anti-scatter grids (ratio 12:1) were used in all the centers.

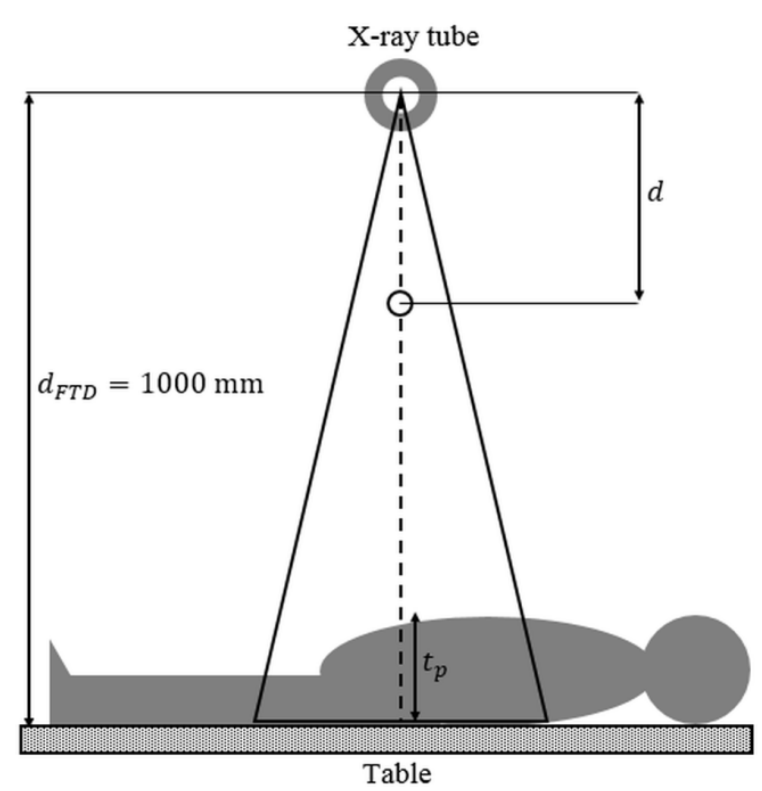

Figure 1. Geometry used for calculation of the entrance dose at the skin surface of a standard patient. 
Table 1. Information of the imaging centers and technical data of the $x$-ray machines.

\begin{tabular}{|c|c|c|c|c|c|c|c|c|c|c|}
\hline $\begin{array}{l}\text { Center } \\
\text { code }\end{array}$ & Manufacturer & $\begin{array}{c}\text { Year of } \\
\text { production }\end{array}$ & $\begin{array}{l}\mathbf{k V p} \\
\max \end{array}$ & $\begin{array}{l}\text { Exposure } \\
\text { setting }\end{array}$ & $\begin{array}{c}\text { Generator } \\
\text { type }\end{array}$ & Film type & $\begin{array}{c}\text { Annual } \\
\text { workload } \\
\text { (patient) }\end{array}$ & $\begin{array}{c}\text { Output } \\
(\mu \mathrm{Gy} / \mathrm{mAs}) \\
\text { at } 80 \mathrm{kVp} \\
\end{array}$ & $\begin{array}{c}\text { HVL } \\
(\mathrm{mm} \mathrm{Al}) \\
\text { at } 70 \mathrm{kVp} \\
\end{array}$ & $\begin{array}{c}\text { Image receptor } \\
\text { (type-speed) }\end{array}$ \\
\hline $\mathrm{C} 1$ & Shimadzu & 1994 & 150 & Manual & 1-phase & AGFA & 27000 & 41.8 & 2.2 & SF-400 \\
\hline $\mathrm{C} 2$ & Varian & 1997 & 150 & Manual & $3 \mathrm{ph}-12 \mathrm{pu}$ & CEA & 57600 & 72.7 & 2.8 & SF-400 \\
\hline $\mathrm{C} 3$ & Varian & 2011 & 150 & Manual & $3 \mathrm{ph}-12 \mathrm{pu}$ & Fujifilm, KODAK & 36000 & 104.3 & 1.9 & SF-400 \\
\hline $\mathrm{C} 4$ & Varian & 2000 & 150 & Manual & $3 \mathrm{ph}-12 \mathrm{pu}$ & AGFA & 13200 & 58.8 & 3.5 & SF-400 \\
\hline $\mathrm{C} 5$ & Shimadzu & 1999 & 150 & Manual & $3 \mathrm{ph}-12 \mathrm{pu}$ & AGFA, CEA, Fujifilm & 36000 & 62.3 & 2.9 & SF-400 \\
\hline C6 & Villa Medical Systems & 1990 & 150 & Manual & 1-phase & Retina, Fujifilm, CEA & 36000 & 20.2 & 2.7 & SF-400 \\
\hline $\mathrm{C} 7$ & Varian & 2003 & 150 & Manual & $3 \mathrm{ph}-12 \mathrm{pu}$ & AGFA & 36000 & - & 3 & SF-400 \\
\hline $\mathrm{C} 8$ & Toshiba & 1999 & 150 & AEC & 1-phase & Kodak & 54000 & 35 & 3.2 & SF-400 \\
\hline
\end{tabular}

Table 2. Patient weight and exposure parameters data across all imaging centers (mean $( \pm \mathrm{SD})$ and min-max range).

\begin{tabular}{|c|c|c|c|c|c|c|}
\hline \multirow{2}{*}{$\begin{array}{c}\text { Center } \\
\text { code }\end{array}$} & \multirow{2}{*}{ Exam } & \multicolumn{2}{|c|}{ Patient data } & \multicolumn{3}{|c|}{ Exposure parameters } \\
\hline & & Number & Weight & $\mathbf{k V p}$ & $\mathbf{m A s}$ & FFD $(\mathrm{cm})$ \\
\hline \multirow{2}{*}{$\mathrm{C} 1$} & Pelvic & 18 & $67.3 \pm 12.7$ & $\begin{array}{c}68.8 \\
(60-75)\end{array}$ & $\begin{array}{c}55.3 \\
(30-75)\end{array}$ & $\begin{array}{c}113.4 \\
(68-120)\end{array}$ \\
\hline & Abdomen & 17 & $65.4 \pm 9.2$ & $\begin{array}{c}69.8 \\
(63-76)\end{array}$ & $\begin{array}{c}58.2 \\
(44-90)\end{array}$ & $\begin{array}{c}115.9 \\
(100-120)\end{array}$ \\
\hline \multirow{2}{*}{$\mathrm{C} 2$} & Pelvic & 11 & $69.9 \pm 10.4$ & $\begin{array}{c}70.1 \\
(66-80)\end{array}$ & $\begin{array}{c}22.2 \\
(14-32)\end{array}$ & $\begin{array}{c}107.3 \\
(100-115)\end{array}$ \\
\hline & Abdomen & 15 & $67.4 \pm 9.5$ & $\begin{array}{c}68.9 \\
(60-84)\end{array}$ & $\begin{array}{c}22.5 \\
(15-90)\end{array}$ & $\begin{array}{c}100.3 \\
(100-105)\end{array}$ \\
\hline \multirow{2}{*}{$\mathrm{C} 3$} & Pelvic & 27 & $69.9 \pm 9$ & $\begin{array}{c}74 \\
(65-86)\end{array}$ & $\begin{array}{c}12.7 \\
(2.56-32)\end{array}$ & $\begin{array}{c}99.8 \\
(80-122)\end{array}$ \\
\hline & Abdomen & 20 & $67.7 \pm 12$ & $\begin{array}{c}76 \\
(65-99)\end{array}$ & $\begin{array}{c}22.5 \\
(10.2-40)\end{array}$ & $\begin{array}{c}99.9 \\
(70-120)\end{array}$ \\
\hline \multirow{2}{*}{$\mathrm{C} 4$} & Pelvic & 22 & $68.5 \pm 11.5$ & $\begin{array}{c}63.3 \\
(55-70)\end{array}$ & $\begin{array}{c}27.1 \\
(20-40)\end{array}$ & $\begin{array}{c}107.5 \\
(95-120)\end{array}$ \\
\hline & Abdomen & 17 & $73.2 \pm 9.2$ & $\begin{array}{c}70.1 \\
(60-75)\end{array}$ & $\begin{array}{c}37.6 \\
(32-51.2)\end{array}$ & $\begin{array}{c}134.1 \\
(80-180)\end{array}$ \\
\hline
\end{tabular}

\begin{tabular}{|c|c|c|c|c|c|c|}
\hline \multirow{2}{*}{$\begin{array}{c}\text { Center } \\
\text { code }\end{array}$} & \multirow{2}{*}{ Exam } & \multicolumn{2}{|c|}{ Patient data } & \multicolumn{3}{|c|}{ Exposure parameters } \\
\hline & & Number & Weight & $\mathbf{k V p}$ & mAs & FFD $(\mathbf{c m})$ \\
\hline \multirow{2}{*}{ C5 } & Pelvic & 22 & $67.2 \pm 7.4$ & $\begin{array}{c}61.1 \\
(54-68)\end{array}$ & $\begin{array}{c}41.5 \\
(15.6-62.5)\end{array}$ & $\begin{array}{c}107 \\
(85-120)\end{array}$ \\
\hline & Abdomen & 7 & $67.6 \pm 9.2$ & $\begin{array}{c}63.8 \\
(56-72)\end{array}$ & $\begin{array}{c}51.7 \\
(32-62.5)\end{array}$ & $\begin{array}{c}118.3 \\
(103-120)\end{array}$ \\
\hline \multirow{2}{*}{ C6 } & Pelvic & 7 & $71.7 \pm 11.4$ & $\begin{array}{c}72.9 \\
(55-103)\end{array}$ & $\begin{array}{c}32.3 \\
(16-50)\end{array}$ & $\begin{array}{c}84.5 \\
(75-100)\end{array}$ \\
\hline & Abdomen & 6 & $76 \pm 12$ & $\begin{array}{c}76.5 \\
(66-84)\end{array}$ & $\begin{array}{c}47.2 \\
(24-75)\end{array}$ & $\begin{array}{c}74.2 \\
(65-100)\end{array}$ \\
\hline \multirow{2}{*}{$\mathrm{C} 7$} & Pelvic & 22 & $73.6 \pm 9.1$ & $\begin{array}{c}65.2 \\
(55-83)\end{array}$ & $\begin{array}{c}25.2 \\
(2.5-40)\end{array}$ & $\begin{array}{c}94.7 \\
(80-126)\end{array}$ \\
\hline & Abdomen & 10 & $70.5 \pm 6.5$ & $\begin{array}{c}66.7 \\
(62-73)\end{array}$ & $\begin{array}{c}36.1 \\
(25-40)\end{array}$ & $\begin{array}{c}102.2 \\
(84-126)\end{array}$ \\
\hline \multirow{2}{*}{$\mathrm{C} 8$} & Pelvic & 20 & $65.1 \pm 12.1$ & $\begin{array}{c}65.7 \\
(56-76)\end{array}$ & $\begin{array}{c}38.6 \\
(16-120)\end{array}$ & $\begin{array}{c}100 \\
(100-100)\end{array}$ \\
\hline & Abdomen & 9 & $67.1 \pm 10.8$ & $\begin{array}{c}67 \\
(60-74)\end{array}$ & $\begin{array}{c}41.3 \\
(19.2-61)\end{array}$ & $\begin{array}{c}102.2 \\
(100-120)\end{array}$ \\
\hline
\end{tabular}

Table 3. Patients parameters data across all imaging centers (mean value, SD and min-max range).

\begin{tabular}{|c|c|c|c|c|c|c|c|c|c|c|c|c|c|}
\hline \multirow{3}{*}{ Exam } & \multicolumn{13}{|c|}{ Patient data } \\
\hline & \multirow{2}{*}{ Number } & \multicolumn{3}{|c|}{ Age (yr) } & \multicolumn{3}{|c|}{ Weight (kg) } & \multicolumn{3}{|c|}{ BMI $\left(\mathrm{kg} / \mathrm{m}^{2}\right)$} & \multicolumn{3}{|c|}{ Thickness (cm) } \\
\hline & & mean & SD & $\min -\max$ & mean & SD & min-max & mean & SD & $\min -\max$ & mean & SD & $\min -\max$ \\
\hline Pelvic & 149 & 39.5 & 19.1 & $15-86$ & 68.8 & 10.4 & $50-90$ & 25.3 & 3.8 & $18.2-35.2$ & 18.4 & 4.7 & $10-34$ \\
\hline \multirow[t]{2}{*}{ Abdomen } & 101 & 40.9 & 18.6 & $17-86$ & 68.9 & 10.2 & $50-90$ & 25 & 3.9 & $17.2-36$ & 21.3 & 6.8 & $10-38$ \\
\hline & \multicolumn{13}{|c|}{ Total number of patients (male, female): $250(125,125)$} \\
\hline
\end{tabular}

Table 4. Exposure parameters and ESDs across all imaging centers for both examinations.

\begin{tabular}{|c|c|c|c|c|c|c|c|c|c|c|c|c|c|}
\hline \multirow{3}{*}{ Exam } & \multicolumn{13}{|c|}{ Exposure parameters } \\
\hline & \multirow{2}{*}{ Number } & \multicolumn{3}{|c|}{$\mathrm{kVp}$} & \multicolumn{3}{|c|}{ mAs } & \multicolumn{3}{|c|}{ FFD (cm) } & \multicolumn{3}{|c|}{ ESD (mGy) } \\
\hline & & mean & SD & $\min -\max$ & mean & SD & $\min -\max$ & mean & SD & $\min -\max$ & mean & SD & $\min -\max$ \\
\hline Pelvic & 149 & 67.1 & 6.9 & $54-103$ & 31.2 & 18.3 & $2.5-120$ & 102.9 & 11.9 & $68-126$ & 2.32 & 1.67 & $0.21-12.4$ \\
\hline \multirow[t]{2}{*}{ Abdomen } & 101 & 70.4 & 6.7 & $56-99$ & 37.5 & 17.2 & $10.2-90$ & 108.5 & 21 & $65-180$ & 3.72 & 3.68 & $0.7-20$ \\
\hline & \multicolumn{13}{|c|}{ Total number of patients (male, female): $250(125,125)$} \\
\hline
\end{tabular}

Table 5. Obtained ESDs (mGy) and exposure parameters (mean value) across all imaging centers as well as literature and international DRLs.

\begin{tabular}{|c|c|c|c|c|c|c|c|c|c|c|c|c|c|c|}
\hline \multirow[b]{2}{*}{ Exam } & & \multirow{2}{*}{$\begin{array}{l}\text { This } \\
\text { study }\end{array}$} & \multicolumn{7}{|c|}{ Previous studies (mean value) } & \multicolumn{3}{|c|}{ HPA DRLs (mean value) } & \multicolumn{2}{|c|}{ DRLs } \\
\hline & & & $\begin{array}{c}\text { Iran } \\
(2015) \\
\end{array}$ & $\begin{array}{l}\text { Korea } \\
(2013) \\
\end{array}$ & $\begin{array}{c}\text { Montenegro } \\
(\mathbf{2 0 1 2}) \\
\end{array}$ & $\begin{array}{l}\text { Ghana } \\
(2012) \\
\end{array}$ & $\begin{array}{l}\text { India } \\
(2010)\end{array}$ & $\begin{array}{l}\text { Iran } \\
(\mathbf{2 0 0 7}) \\
\end{array}$ & $\begin{array}{l}\text { Korea } \\
(2007) \\
\end{array}$ & $\begin{array}{c}\mathrm{UK} \\
(2000) \\
\end{array}$ & $\begin{array}{c}\mathrm{UK} \\
(2005) \\
\end{array}$ & $\begin{array}{c}\mathbf{U K} \\
(2010) \\
\end{array}$ & $\begin{array}{c}\text { EC } \\
(1996) \\
\end{array}$ & $\begin{array}{l}\text { IAEA } \\
(1996) \\
\end{array}$ \\
\hline \multirow{3}{*}{$\begin{array}{l}\text { Pelvic } \\
\text { (AP) }\end{array}$} & $\mathrm{kVp}$ & 67.1 & 68.8 & 75 & & & 68 & 68 & 72 & 74 & 75 & 75 & $75-90$ & \\
\hline & mAs & 31.2 & 34.8 & 42 & & & 69 & 66 & 31 & 35 & 32 & 33 & & \\
\hline & $\operatorname{ESD}\left(\right.$ mean, $\left.3^{\text {rd }} \mathbf{Q}\right)$ & $(2.32,2)$ & 1.90 & 2.34 & 4.7 & 14.8 & 6.34 & 2.84 & 2.44 & 3.6 & 3.06 & 3.2 & 10 & 10 \\
\hline \multirow{3}{*}{$\begin{array}{l}\text { Abdomen } \\
\text { (AP) }\end{array}$} & $\mathrm{kVp}$ & 70.4 & 71.1 & 76 & & & 67 & 67 & 74 & 74 & 76 & 76 & & \\
\hline & mAs & 37.5 & 35.8 & 42 & & & 67 & 65 & 33 & 46 & 31 & 41 & & \\
\hline & $\operatorname{ESD}\left(\right.$ mean, $\left.3^{\text {rd }} \mathbf{Q}\right)$ & $(3.72,10)$ & 2.07 & 2.46 & 4 & & 5.61 & 3.87 & 2.33 & 4.7 & 3.54 & 3.6 & & 10 \\
\hline
\end{tabular}


Table 2 shows the mean and standard deviation of patient weight and exposure parameters for pelvis and abdomen examinations. The information provided in this table offers a convenient way to evaluate radiologic technologist working habits among imaging centers in order to compare exposure setting parameters for the same examination. Almost all centers received more than 15 patients per procedure on average, which is in full compliance with the IAEA minimum acceptance criteria, which is 10 patients for each examination [19]. Tables 3-4 present the patient individual information and exposure conditions as well as obtained ESDs among imaging centers for both examinations. Exposure parameters, mean and 3rd quartile of ESDs are shown in Table 5. This important findings provided us with a comparable situation in our results with studies in other countries and international DRLs [21-23].

\section{Discussion}

In recent years, the growth rate of X-ray generating devices has increased and nowadays plays a critical role in the diagnosis of diseases. In Iran, 18,867,000 diagnostic X-ray imaging were carried out on $12,963,000$ patients in 2003, i.e. 363 examinations per 1000 inhabitants [17].

As presented in Table 5, the findings of this research indicate that mean entrance skin doses for both examinations (pelvis: $2.3 \mathrm{mGy}$ and abdomen: $3.7 \mathrm{mGy}$ ) are lower than the IAEA and EC dose reference levels (pelvis: $9 \mathrm{mGy}$ and abdomen: $10 \mathrm{mGy}$ ) [18,22]. Care must be taken that the international dose reference levels are presented as 3rd quartile. As mentioned earlier, radiology technologists who participated in this study set exposure parameters $(\mathrm{kVp}$ and FFD) lower than the recommended range defined by EC that is 75-90 for $\mathrm{kVp}$ and 100-150 for FFD (cm) in a standard pelvis examination. Despite the fact that mean applied $\mathrm{kVps}$ for pelvis and abdomen examinations were 67 and 70 and mean applied FFDs were 103 and $109 \mathrm{~cm}$, respectively, the images taken had acceptable quality. In respect of radiation physics fundamentals, using low $\mathrm{kVp}$ and FFD must result in more entrance skin dose due to high intensities of the X-ray field and this represents a stark contrast to our finding. The explanation for this disparity lies in some noteworthy points. It should not be expected that applying "good radiographic technique" parameters, as recommended in European Commission EUR $16260 \mathrm{EN}$, result in $10 \mathrm{mGy}$ absorb dose to the patient's pelvis [22]. This is because other factors like mAs, BMI and thickness must also be considered. The amount of $10 \mathrm{mGy}$ is a maximum level that is considered as the ultimate limit. Reported findings of other studies as shown in Table 5 also confirms this claim. A comparison of exposure parameters for abdomen with the EC criteria is not possible as there is no recommended "good radiographic technique" characteristics and DRLs.

As Table 2 shows, nearly all centers received more than 10 patients per a procedure (pelvis or abdomen) except C6 that can be partly relate to limited ability of applying high $\mathrm{kVp}$ and mAs. As Table 3 shows, mean value of physical parameters such as age, weight and BMI of patients who participated in this study are 40 year, $69 \mathrm{~kg}$ and $25 \mathrm{~kg} / \mathrm{m}^{2}$, respectively for both pelvis and abdomen examinations. This reported values are in good agreement with the previous Iranian studies and the IAEA Asian standard patient specifications. The average annual patient load across all centers are more than 37000 patients, i.e. more than 100 patients a day. $\mathrm{C} 2$ center had the maximum amount of annual patient load and $\mathrm{C} 4$ was an imaging center with minimum referred patients. There was no clear association between daily workload and patient doses.

As Table 5 shows, the $\mathrm{kVp}$ values obtained in this study for pelvis examination were lower than those of obtained in the Korea (2007, 2013), India, three the UK studies, EC and the previous studies which have been done in Iran (2007 and 2015) $[3,5,24]$. This is also true for abdomen examination if India and Iran (2007) studies be ignored [1]. There are several reasons why Iranian radiology technologists did not set higher applied voltages. It was seen that, in the case of technical problems that are related to high-voltage burden to the radiology devicetypically $\mathrm{kVps}$ higher than 85 or 90-service provider companies do not provide any support services. In other words, the radiology technologists are facing a major hurdle to set $\mathrm{kVps}$ higher than 85 to avoid damaging the tubes. This is mainly due to device aging as well as frequent repairs on X-ray tubes and generators. Another reason for applying low voltages is a wrong mindset of Iranian technologists toward scattered and leakage radiation level in a radiography control room, especially in the cases of high $\mathrm{kVp} \mathrm{X}$-ray examinations like procedures in this study. Particular attention should be paid for bridge the gap between theoretical and clinical knowledge of technologists in the form of on-the-job training programs to diminish this problem. Also, the tube loadings (mAs) reported in this work for pelvis examination are lower than the corresponding values in all the reviewed literature. The tube loadings obtained from abdomen examination are more than Korea (2007) and UK (2005) results, comparable to Iran (2015) and lower than the results of other studies. The main reason for low obtained ESDs in this study is due to low applied tube loadings. As shown in Table 5, it is fully clear that the relationship between radiation dose and $\mathrm{mAs}$ is linear.

Such studies should be carried out on a larger scale across the country, also covering digital radiography systems, CT scans and interventional radiology procedures to set up a valid national reference levels in the country.

\section{Conclusions}

This research is a regional patient dose survey for Khuzestan, southwest of Iran. Therefore, the authors recommend that DRLs obtained in this region, which is the first available data, can be used as local DRLs for pelvis and abdomen examinations. This work also provides evidence that dose reduction in the conventional X-ray examinations is feasible through adequate education of radiology technology undergraduate students by updated theoretical and clinical 
course materials, on-the-job training workshops for staffs, implementation of systematic QA and QC programs and close cross collaboration between physicists and physicians in medical imaging centers.

\section{Acknowledgements}

This research was supported by Behbahan Faculty of Medical Sciences (Research Project No. 9407).

\section{References}

[1] Sonawane AU, Shirva VK, Pradhan AS. Estimation of skin entrance doses (SEDs) for common medical X-ray diagnostic examinations in India and proposed diagnostic reference levels (DRLs). Radiat Prot Dosimetry. 2010;138(2):129-136.

[2] Ofori EK, Antwi WK, Scutt DN, Ward M. Optimization of patient radiation protection in pelvic X-ray examination in Ghana. J Appl Clin Med Phys. 2012;13(4):3719.

[3] Kim YH, Choi JH, Kim CK, et al. Patient dose measurements in diagnostic radiology procedures in Korea. Radiat Prot Dosimetry. 2007;123(4):540-545.

[4] Milatović A, Ciraj-Bjelac O, Ivanović S, et al. Patient dose measurements in diagnostic radiology procedures in Montenegro. Radiat Prot Dosimetry. 2012;149(4):454-463.

[5] Seo D, Jang S, Kim J, et al. A comparative assessment of entrance surface doses in analogue and digital radiography during common radiographic examinations. Radiat Prot Dosimetry. 2014;158(1):22-27.

[6] Ciraj O, Marković S, Kosutić D. First results on patient dose measurements from conventional diagnostic radiology procedures in Serbia and Montenegro. Radiat Prot Dosimetry. 2005;113(3):330-335.

[7] Hart D HMC, Shrimpton PC. Doses to Patients from Radiographic and Fluoroscopic X-ray Imaging Procedures in the UK - 2005 Review. Chilton: Health Protection Agency; 2007.

[8] Hart D HMC, Shrimpton P C. Doses to Patients from Radiographic and Fluoroscopic X-ray Imaging Procedures in the UK - 2010 Review. Chilton: Health Protection Agency; 2012.

[9] Zaidi H. Medical physics in developing countries: looking for a better world. Biomed Imaging Interv J. 2008;4(1):e29.

[10] Mahdavi SR, Rasuli B, Niroomand-Rad A. Education and training of medical physics in Iran: The past, the present and the future. Phys Med. 2017;36:66-72.

[11] Shirin Shandiz M, Bahreyni Toosi MT, Farsi S, Yaghobi K. Local reference dose evaluation in conventional radiography examinations in Iran. J Appl Clin Med Phys. 2014;15(2):4550.

[12] Rasuli B, Mahmoud-Pashazadeh A, Tahmasebi Birgani MJ, et al. Quality Control of Conventional Radiology Devices in Selected Hospitals of Khuzestan Province, Iran. Iranian J Med Phys. 2015;12(2):101-108.

[13] Shahbazi-Gahrouei D, Baradaran-Ghahfarokhi M. Assessment of entrance surface dose and health risk from common radiology examinations in Iran. Radiat Prot Dosimetry. 2013;154(3):308-313.

[14] Khosravi HR, Gholamalizadeh Z, Zadeh MRH, et al. Patient Doses Reduction in Simple Radiographic Examinations in Busy Radiology Departments. Med Phys. 2011;38(6):3414.

[15] Khoshdel-Navi D, Shabestani-Monfared A, Deevband MR, et al. Local-Reference Patient Dose Evaluation in Conventional Radiography Examinations in Mazandaran, Iran. J Biomed Phys Eng. 2016;6(2):61-70.

[16] Rasuli B, Ghorbani M, Juybari RT. Radiation dose measurement for patients undergoing common spine medical x-ray examinations and proposed local diagnostic reference levels. Radiat Meas. 2016;87:29-34.

[17] Rasuli B, Mahmoud-Pashazadeh A, Ghorbani M, et al. Radiation dose measurement for patients undergoing common spine medical X-ray examinations and proposed local diagnostic reference levels. J Appl Clin Med Phys. 2016;17(1):5860.

[18] IAEA. Optimization of the Radiological Protection of Patients Undergoing Radiography, Fluoroscopy and Computed Tomography: IAEA; 2004.

[19] IAEA. Dosimetry in Diagnostic Radiology: An International Code of Practice; 2007.

[20] Scally AJ. Recommended Standards for the Routine Performance Testing of Diagnostic X-Ray Imaging Systems. IPEM Report 91. York: Institute of Physics and Engineering in Medicine, 2005.

[21] EC. European Guidelines on Quality Criteria for Diagnostic Radiographic Images. Luxembourg: European Commission, 1996.

[22] EC. Radiation Protection 109: Guidance on Diagnostic Reference Levels (DRLs) for Medical Exposures. Directorate-General Environment, Nuclear Safety and Civil Protection; 1999.

[23] IAEA. International Basic Safety Standards for Protection Against Ionizing Radiation and for the Safety of Radiation Sources. Safety Series. VIENNA: IAEA, 1996.

[24] Hart D, Shrimpton PC. Fourth review of the UK national patient dose database. Br J Radiol. 2012;85(1018):e957-e958. 